\title{
Applied Zooarchaeology: Five Case Studies. By Steve Wolverton, Lisa Nagaoka, and Torben C. Rick. 2016. Eliot Werner Publications, Clinton Corners, NY. 130 pp.
}

\author{
Jonathan Dombrosky ${ }^{1 *}$ \\ ${ }^{1}$ Department of Anthropology, University of New Mexico, Albuquerque, NM, USA. \\ *jdombrosky@unm.edu
}

Received November 26, 2016

Accepted December 21, 2016

OPEN ACCESS $_{\text {DOI } 10.14237 / \mathrm{ebl} .7 .1 .2016 .832}$

Copyright (c) 2016 by the author(s); licensee Society of Ethnobiology. This is an open-access article distributed under the terms of the Creative Commons Attribution-NonCommercial 4.0 International Public License (https://creativecommons.org/licenses/by-nc/4.0), which permits non-commercial use, distribution, and reproduction in any medium, provided the original author and source are credited.

I am a former student of two of the three authors of Applied Zooarchaeology: Five Case Studies-Steve Wolverton and Lisa Nagaoka. They ignited and fostered my interest in applied zooarchaeology. So, I eagerly anticipated the release of this book, and jumped at the chance to review it. Perhaps it would be predictable if I gave this book a positive review, but that is exactly what I am going to do anyway. The shamelessness of my positive review derives from three excellent characteristics of this book: it is concise, (zoo)archaeological data quality is a recurrent theme, and it serves as a guide for achieving interdisciplinary research.

I do not only mean that this is a short book when I say that it is concise. The writing style is succinct, jargon is kept to a minimum, and each point is direct and cogent. In other words, Applied Zooarchaeology: Five Case Studies is one well-written book. In no way, however, are deeper points sacrificed. For instance, a discussion about the philosophical merit of applied zooarchaeological research starts on page one. A book with such a clear writing style comes at an opportune time for archaeologists who study humanenvironmental impacts in deep time. If we are indeed living in a post-truth era (sensu Keyes 2004), then questions related to how archaeologists should balance the integrity of their research while still effectively communicating its merits to the public have never been so important. In my opinion, Applied Zooarchaeology achieves just such a balance because limitations of the (zoo)archaeological record are clearly delineated, which puts the questions that can be addressed on firmer ground.
An honest, upfront consideration of data quality is necessary if (zoo)archaeological data are to have any impact on conservation/restoration science-a point that has received wide exposure in the broader scientific literature (see Boivin et al. 2016; Westaway and Lyman 2016; Zeder et al. 2016). The authors of Applied Zooarchaeology underscore this point, and explain that "One of the most important differences between environmental scientists and archaeologists is that the former have explicitly recognized policies and practices for ensuring data quality, or information that produces valid results" (p. 9). In other words, the people applied (zoo)archaeologists are writing forrestoration ecologists, wildlife managers, etc.-have legitimate concerns about the validity of archaeological data. Thus, applied (zoo)archaeologists must constantly reaffirm why they know what they do at the most basic level, which means demonstrating that identifications are correct, that preservation is not an issue, and that the quantitative methods employed are appropriate. One of the other great things about this book is that it shows that while these are very real problems, they are by no means insurmountable. Nowhere is this more clearly illustrated than in the second chapter. In this chapter, the authors tackle how the differential preservation of unionidfreshwater mussel—shells can be assessed to test if the species composition of a zooarchaeological assemblage is representative of a past mussel community.

Chapter six is my favorite chapter because it highlights professional encounters that Steve Wolverton had with wildlife managers and conservation 
biologists. This chapter helps answer the question: How exactly do archaeologists take their research and make it mean something that helps solve actual conservation problems? In the subsection entitled "Interactions with Biologists," three separate interactions with the professional biological community are recounted when Wolverton was working to disseminate research related to differences in prehistoric and modern white-tailed deer body size in central Texas. In his first interaction, he presented his research at the 2006 Southwestern Association of Naturalists (SWAN) conference in Colima, Mexico. Much to his chagrin, the crowd was not instantly won over by the novelty of zooarchaeological data or the deep time perspective; they were far more concerned about the appropriateness of archaeological data in answering the questions that they were interested in. In two subsequent interactions-one at a Texas Parks and Wildlife Department (TPWD) workshop in 2006 and a presentation to the Department of Biology at Texas State University in 2007-Wolverton continued to hone and improve his research by directly engaging in the issues of data quality that biologists were concerned about. The authors explain, "A fatal mistake would have been to dismiss questions about representative sampling" (p. 84). This chapter is great because it highlights the fact that this research is not—and should not be-just for archaeologists. We must put on our "anthropologist hats" (p. 82), listen to the legitimate concerns of the people we want to work with, and tailor our research accordingly.

After reading this book, it becomes clear that a vague programmatic appeal about the utility of deep time to conservation/restoration science is simply not enough. The archaeological literature on humanenvironmental impacts and what it means for preserving or conserving biota has become somewhat redundant. It is assumed that when new archaeological research is completed, and novel humanenvironmental impacts are found, that these findings are inherently important for either managing, conserving, or restoring biodiversity in the future. For biologists - who are usually well-versed in thinking on evolutionary timescales - the dictum that "history matters" is a given; it is up to (zoo)archaeologists to show why and how it matters. This requires tackling local problems and demonstrating how (zoo) archaeological data can be integrated into conservation/restoration programs. Applied Zooarchaeology: Five Case Studies shows how locally impactful, interdisciplinary historical ecological research can be achieved in a highly digestible way. As such, it is well worth the read.

\section{References Cited}

Boivin, N. L., M. A. Zeder, D. Q. Fuller, A. Crowther, G. Larson, J. M. Erlandson, T. Denham, and M. D. Petraglia. 2016. Ecological Consequences of Human Niche Construction: Examining LongTerm Anthropogenic Shaping of Global Species Distributions. Proceedings of the National Academy of Sciences 113:6388-6396. DOI:10.1073/ pnas.1525200113.

Keyes, R. 2004. The Post-Truth Era: Dishonesty and Deception in Contemporary Life. St. Martin's Press, New York.

Westaway, M. C., and R. L. Lyman. 2016. The Need to Overcome Risks Associated with Combining Inadequate Paleozoological Records and Conservation Biology. Proceedings of the National Academy of Sciences 113:E4757-E4758. DOI:10.1073/ pnas.1609950113.

Zeder, M. A., T. Denham, J. M. Erlandson, N. L. Boivin, A. Crowther, D. Q. Fuller, G. Larson, and M. D. Petraglia. 2016. Reply to Westaway and Lyman: Emus, Dingoes, and Archaeology's Role in Conservation Biology. Proceedings of the National Academy of Sciences 113:E4759-E4760. DOI:10.1073/pnas.1610697113. 